Revista Universo Contábil, ISSN 1809-3337

Blumenau, v. 10, n. 1, p. 67-83, jan./mar., 2014

doi:10.4270/ruc.2014104

Disponível em www.furb.br/universocontabil

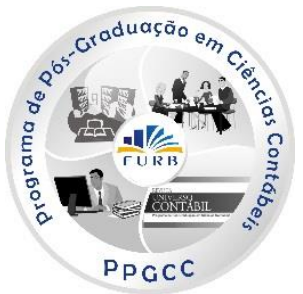

CONVERGÊNCIA INTERNACIONAL DAS NORMAS CONTÁBEIS E AS

ALTERAÇÕES NA ESTRUTURA DO RELATÓRIO POR SEGMENTOS: DA DIVULGAÇÃO VOLUNTÁRIA AO ADVENTO DO CPC 221

\title{
INTERNATIONAL CONVERGENCE OF ACCOUNTING STANDARDS AND CHANGES IN THE SEGMENT REPORT STRUCTURE: FROM VOLUNTARY DISCLOSURE TO CPC 22 ADVENT
}

\section{CONVERGENCIA INTERNACIONAL DE LAS NORMAS CONTABLES Y LOS CAMBIOS EN LA ESTRUCTURA DE INFORME POR SEGMENTO: DIVULGACIÓN VOLUNTARIA ADVIENTO DEL CPC 22}

Eliandro Schvirck

Doutor em Administração pela Universidade Federal de Santa Catarina Professor do Curso de Ciências Contábeis na UTFPR - Câmpus Pato Branco Endereco: Via do Conhecimento, $\mathrm{Km} 01$ CEP: 85503-390 - Pato Branco - PR E-mail: eliandro@utfpr.edu.br Telefone: (46) 3220-2527

Rogério João Lunkes Pós-Doutor em Contabilidade pela Universidad de Valência, Espanha Professor do Departamento de Ciências Contábeis e do Programa de Pós-Graduação em Contabilidade e Administração da UFSC Endereço: Campus Universitário Reitor João David Ferreira Lima - Trindade CEP: 88040-380 - Florianópolis - SC E-mail: rogeriolunkes@hotmail.com Telefone: (48) 3721-6634

Valdirene Gasparetto Doutora em Engenharia de Produção pela Universidade Federal de Santa Catarina Professora do Departamento de Ciências Contábeis e do Programa de Pós-Graduação em Contabilidade da UFSC Endereço: Campus Universitário Reitor João David Ferreira Lima - Trindade CEP: 88040-380 - Florianópolis - SC E-mail: valdirene.gasparetto@ufsc.br (48) $3721-6512$

José Alonso Borba

Pós-Doutor em Ciências Contábeis pela Rutgers University e École des Hautes Études Commerciales de Montréal Professor do Departamento de Ciências Contábeis e do Programa de Pós-Graduação em Contabilidade e Administração da UFSC Campus Universitário Reitor João David Ferreira Lima - Trindade CEP: 88040-380 - Florianópolis - SC E-mail: jalonso@cse.ufsc.br

(48) 3721-9383

\footnotetext{
1 Artigo recebido em 29.04.2013. Revisado por pares em 25.11.2013. Reformulado em 05.03.2014. Recomendado para publicação em 27.03.2014 por Carlos Eduardo Facin Lavarda. Publicado em 31.03.2014. Organização responsável pelo periódico: FURB.
} 


\section{RESUMO}

A adoção das normas internacionais de contabilidade (IFRS) no Brasil motivou diversas alterações nos procedimentos das empresas. Neste sentido, o objetivo deste estudo foi avaliar o impacto na estrutura dos relatórios de empresas que voluntariamente divulgaram segmentos antes da promulgação do CPC 22. O estudo adotou abordagem descritiva e foi realizado por meio de levantamento de dados em notas explicativas de 47 companhias abertas que compunham o índice $\mathrm{IBrX} 50$ no mês de dezembro de 2012. O período da pesquisa compreendeu os exercícios de 2008 a 2011. Os resultados da pesquisa mostram que a adoção do CPC 22 foi relevante ao ampliar o número de empresas que publicaram o relatório, de forma voluntária em torno de $15 \%$ das companhias fez a divulgação, a partir de 2010 a publicação foi feita por $96 \%$ das empresas. O impacto na estrutura das demonstrações das empresas que divulgaram de forma voluntária o relatório por segmentos, pode ser notado pela agregação de informações selecionadas que não são apresentadas nas demonstrações consolidadas, tais como medidas de resultado não previstas na legislação, a possibilidade de combinar segmentos de acordo com a estrutura interna utilizada na gestão da empresa e a informação de quem é o principal gestor na tomada de decisões da companhia.

Palavras-chave: relatório por segmentos; CPC 22; evidenciação; companhias abertas.

\section{ABSTRACT}

The adoption of international accounting standards (IFRS) in Brazil motivated several changes in business procedures. In this sense, the objective of this study was to evaluate the impact on the structure of the reports in companies that voluntarily disclosed segments before the promulgation of CPC 22. The study adopted a descriptive approach and was conducted through data survey in the notes of 47 public companies that comprised the IBrX 50 index in December 2012. The study period comprised the years from 2008 to 2011. The research results show that the adoption of CPC 22 was relevant to expand the number of companies that published the report on a voluntary basis, around $15 \%$ of the companies made the disclosure, as of 2010 the publication was made by $96 \%$ of the companies. The impact on the financial structure of the companies that voluntarily disclosed the report by segments, can be noticed by the aggregation of selected information that are not presented in the consolidated statements, such as outcome measures not provided for in the legislation, the possibility of combining segments according to the internal structure used in the management of the company and information about who is the main manager in the decision making of the company.

Keywords: segment report; CPC 22; disclosure; public companies.

\section{RESUMEN}

La adopción de normas internacionales de contabilidad (IFRS) de Brasil llevó a varios cambios en los procesos de negocio. En este sentido, el objetivo de este estudio fue evaluar el impacto en la estructura de los informes de las empresas que se hayan publicado voluntariamente segmentos antes de la promulgación de la CPC 22. El estudio adoptó un enfoque descriptivo y se llevó a cabo a través de los datos de la encuesta en las notas de 47 empresas públicas que integraban la IBrX 50 de diciembre de 2012. El período de estudio abarcó los años 2008 a 2011. Los resultados de la investigación muestran que la adopción del CPC 22 era importante para ampliar el número de empresas que publicaron el informe, de forma voluntaria en torno al $15 \%$ de las empresas realiza la divulgación, a partir de 2010, 
la publicación se hizo en un $96 \%$ de empresas. El impacto en la estructura financiera de las empresas que voluntariamente dan a conocer el informe por segmentos, se puede notar por la agregación de información seleccionada que no se presenta en los estados financieros, tales como medidas de resultados no previstos en la legislación, la posibilidad de combinar segmentos de acuerdo con la estructura interna que se utiliza en la gestión de la empresa y detalles de quién es el gerente de más alto en la toma de decisiones de la empresa.

Palabras clave: información por segmentos, CPC 22, divulgación, las empresas portátiles.

\section{INTRODUÇÃO}

A contabilidade brasileira vem passando por mudanças desde o início do processo de convergência aos padrões contábeis internacionais (IFRS - International Financial Reporting Standards). Dentre as normas incluídas na prática contábil das empresas, o pronunciamento técnico CPC 22, referente a informações por segmento, foi pioneiro na normatização compulsória de informações por segmento no Brasil.

Anterior ao CPC 22 houve orientações, por parte da CVM (Comissão de Valores Mobiliários), para que as empresas divulgassem informações por segmentos de negócios e geográficos nos parâmetros propostos pelo IAS 14 (International Accounting Standard), do IASB (International Accounting Standards Board), porém, tais orientações não tiveram caráter obrigatório. Apesar disso, estudos mostram que algumas empresas divulgaram voluntariamente, no Brasil, informações por segmentos antes de 2010, ou seja, antes da vigência do CPC 22 (VASCONSELOS e SZUSTER, 2003; CRUZ et al., 2011; SCHVIRCK e GASPARETTO, 2011) baseando-se, normalmente, no IAS 14.

De acordo com Vasconselos e Szuster (2003), a falta de uma norma que regulamentasse a divulgação de informações por segmentos fazia com que empresas que possuíssem ações em bolsas internacionais, publicassem tais informações em outros mercados, porém, não divulgavam o mesmo relatório no mercado brasileiro.

As normas sobre relatórios por segmentos, IFRS 8, CPC 22 e SFAS 131 (Statement Financial Accounting Standards), determinam a adoção de abordagem gerencial na definição das informações divulgadas, ou seja, que as informações sejam divulgadas de acordo com a estrutura utilizada na tomada de decisões do principal gestor de operações, diferente das orientações normativas anteriores (IAS 14 e SFAS 14), que requeriam a divulgação dos segmentos por linha de negócios e por atuação geográfica.

Assim, a abordagem gerencial preconizada pelo IFRS 8 e traduzida no CPC 22, é um ponto que proporciona grande discricionariedade ao gestor na divulgação da informação, pois faz com que o relatório por segmentos de cada organização apresente características específicas, dependendo da estrutura interna e da abordagem empregada na tomada de decisões nessas organizações.

Nos mercados norte-americano e europeu, diversos estudos mostram que as empresas alteraram a maneira de divulgar informações por segmentos a partir do advento do IFRS 8 e SFAS 131 (NICHOLS, STREET e GRAY, 2000; HERMANN e THOMAS, 2000; BERGER e HANN, 2003; ETTREDGE et al., 2006; MARDINI, CRAWFORD e POWER, 2012 e NICHOLS, STREET e CEREOLA, 2012). No Brasil, também é importante pesquisar quais os impactos da adoção do CPC 22 na estrutura dos relatórios publicados pelas companhias abertas que divulgaram voluntariamente informações por segmentos antes de 2010.

Neste contexto, o objetivo deste estudo é verificar, nas companhias que publicaram voluntariamente informações por segmentos em 2008 e 2009, se o CPC 22, cujas regras passaram a ser válidas a partir do exercício de 2010, gerou alterações na forma de divulgação 
do relatório por segmentos. Com o trabalho se busca compreender se a flexibilidade proporcionada pela norma impactou a maneira de as empresas divulgarem essas informações.

Para atingir o objetivo proposto, estruturou-se este estudo em cinco seções, sendo a primeira esta, de introdução. Na segunda seção apresenta-se o referencial teórico que sustenta a pesquisa; na terceira mostram-se os procedimentos metodológicos empregados; na quarta são apresentados os resultados da pesquisa realizada; e na quinta evidenciam-se as conclusões do estudo. Ao final são apresentadas as referências.

\section{REFERENCIAL TEÓRICO}

O estudo de informações por segmentos no mercado brasileiro é um tema recente e por isso poucas pesquisas foram desenvolvidas até o momento. $\mathrm{O}$ referencial teórico deste estudo apresenta a evolução normativa sobre segmentos, com ênfase no mercado brasileiro. Os estudos anteriores internacionais abordaram a mudança normativa ocorrida no ambiente do IASB e do FASB, já os realizados no Brasil abordaram a divulgação voluntária do relatório por segmentos.

\subsection{Evolução Normativa}

Os primeiros passos para a normatização de informações por segmento no Brasil ocorreram por meio do parecer de orientação 24/92 emitido pela CVM, que estimulou e incentivou o enriquecimento da informação pública a partir de procedimentos como a publicação de notas com os "resultados por linha de produtos ou negócios, em especial referente às demonstrações consolidadas" (CVM, 1992).

No setor de energia elétrica, por meio da Resolução Nº 001/97 da ANEEL (Agência Nacional de Energia Elétrica), a partir de 1997 passou a ser normatizada para as companhias de eletricidade a contabilização das operações segmentadas em geração, distribuição e transmissão, por meio da publicação do plano de contas único para o setor. Com a Resolução $\mathrm{n}^{\mathrm{o}}$. 444/2001 o plano de contas único foi revisado e procedimentos foram ajustados de forma a buscar convergência com CVM, CFC (Conselho Federal de Contabilidade), IBRACON (Instituto dos Auditores Independentes do Brasil) e IASC (International Accounting Standards Committee), precursor do IASB.

No contexto das companhias abertas, a CVM emitiu em 2004 o Ofício Circular CVM/SNC/SEP 01/2004, onde detalhava o objetivo dos relatórios por segmentos e reforçava o incentivo às empresas no sentido de divulgarem informações por segmento de acordo com os parâmetros expostos pelo IAS 14. Posteriormente, em 2007, a partir de Ofício Circular, reforçou o estímulo à divulgação de relatório por segmentos. No entanto, até então as orientações da CVM apenas estimulavam, mas não exigiam a publicação.

A convergência e adoção das normas internacionais (IFRS) no Brasil ocorreram gradativamente. Em 2009, a deliberação CVM 582/09 instituiu o CPC 22, aplicando no Brasil o IFRS 8, que alinhou as exigências de divulgação de informações por segmento às normas internacionais a partir das demonstrações financeiras do exercício de 2010.

A divulgação de informações por segmento acontece de forma normatizada há vários anos em mercados regidos pelo IASB e pelo FASB (Financial Accounting Standards Board). De acordo com Mourad (2009), os primeiros atos normativos referentes às informações segmentadas ocorreram na década de 1960. O SFAS 14 do FASB, normatizando os relatórios por segmentos e que serviu de base para as normas do IASB, foi publicado em 1976. O

Quadro 1 apresenta acontecimentos que contribuíram para a evolução normativa da divulgação de informações por segmentos. 
Quadro 1: Evolução normativa da di vul gação de informações por segmento no contexto do IASB, FASB e CPC.

\begin{tabular}{|c|c|}
\hline Ano & Histórico \\
\hline 1964 & $\begin{array}{l}\text { A Bolsa de Valores de Londres requereu que empresas listadas fornecessem dados segmentados } \\
\text { sobre o lucro e o faturamento de diferentes tipos de atividades. }\end{array}$ \\
\hline 1967 & $\begin{array}{l}\text { AICPA procurou melhorar os relatórios com o acréscimo de informações e exigiu das empresas } \\
\text { diversificadas que divulgassem dados por segmentos de maneira voluntária e complementar. }\end{array}$ \\
\hline 1969 & $\begin{array}{l}\text { SEC iniciou estudos sobre o impacto dos relatórios por segmento e apresentou uma série de } \\
\text { exigências às empresas listadas. }\end{array}$ \\
\hline 1970 & $\begin{array}{l}\text { Empresas dos EUA começaram a apresentar ao mercado um relatório voluntário por segmentos } \\
\text { de acordo com as instruções da SEC e da AICPA. }\end{array}$ \\
\hline \multirow[t]{2}{*}{1976} & $\begin{array}{l}\text { Foi normatizada pelo FASB, com a introdução do SFAS 14, a exigência de dados sobre linha de } \\
\text { negócios, informação requerida pela SEC desde } 1970 \text {. }\end{array}$ \\
\hline & $\begin{array}{l}\text { Proposta da ONU para relatórios por segmentos baseada em linha de negócios e análises } \\
\text { geográficas das vendas, lucro operacional, gastos de capital e empregados. }\end{array}$ \\
\hline 1980 & $\begin{array}{l}\text { IASC emitiu uma proposta para divulgação de lucros provenientes da receita de vendas e dos } \\
\text { ativos identificáveis para segmentos industriais e geográficos. }\end{array}$ \\
\hline 1981 & $\begin{array}{l}\text { Emissão do IAS 14, exigia a divulgação da receita e dos ativos utilizados tanto para se gmentos } \\
\text { de negócios e geográficos. Baseado no SFAS 14, de } 1976 .\end{array}$ \\
\hline 1992 & $\begin{array}{l}\text { No Brasil, a CVM emitiu o parecer de orientação } 24 / 92 \text { que incentivava as empresas a divulgar } \\
\text { informações sobre o resultado das linhas de produtos ou negócios. }\end{array}$ \\
\hline \multirow[t]{3}{*}{1997} & $\begin{array}{l}\text { IASC publicou o IAS } 14 \text { (Revisada), tendo por objetivo estabelecer as informações do relatório } \\
\text { por segmentos por linha de atividade e áreas geográficas. }\end{array}$ \\
\hline & $\begin{array}{l}\text { FASB editou a SFAS 131, em substituição à SFAS 14, normatizando a divulgação por segmento } \\
\text { e inserindo o conceito da abordagem gerencial à informação divulgada. }\end{array}$ \\
\hline & $\begin{array}{l}\text { No Brasil, a Agência Nacional de Energia Elétrica (ANEEL) editou a resolução } 001 / 97 \text { que } \\
\text { criou um plano de contas único para o setor no qual existia a obrigatoriedade da elaboração de } \\
\text { informações por segmento de negócios. }\end{array}$ \\
\hline 2001 & $\begin{array}{l}\text { A ANEEL emitiu a Resolução No. 444/01 que revisou o plano de contas único ajustando-o as } \\
\text { normas internacionais. }\end{array}$ \\
\hline 2004 & $\begin{array}{l}\text { No Brasil, o Ofício Circular CVM/SNC/SEP } 01 / 2004 \text { incentivava as companhias abertas a } \\
\text { divulgarem informações por segmento, em acordo com o IAS } 14 \text {. }\end{array}$ \\
\hline 2006 & $\begin{array}{l}\text { O IASB emitiu o ED 8, que posteriormente tornou se a IFRS } 8 \text {, esta alinhou as exigências do } \\
\text { IASB, no IAS } 14 \mathrm{R} \text {, com as normas do SFAS } 131 \text { do FASB, tendo como principal mudança a } \\
\text { adoção da abordagem gerencial na divulgação de segmentos. }\end{array}$ \\
\hline 2009 & $\begin{array}{l}\text { No Brasil a deliberação CVM 582/090 institui o CPC } 22 \text { que alinha as exigências de divulgação } \\
\text { de segmentos às normas internacionais (IFRS-8), e passou a vigorar nas demonstrações } \\
\text { referentes ao exercício de } 2010 \text {. }\end{array}$ \\
\hline 2012 & $\begin{array}{l}\text { O FASB publicou o estudo de pós implementação do SFAS 131, visando possíveis ajustes na } \\
\text { norma. }\end{array}$ \\
\hline 2013 & $\begin{array}{l}\text { O IASB publicou o estudo de pós implementação do IFRS 8, analisando possíveis ajustes na } \\
\text { norma. }\end{array}$ \\
\hline
\end{tabular}

Fonte: Elaborado pelos autores com base em Mourad (2009) e atualizado com fatos posteriores.

\section{Conforme demonstrado no}

Quadro 1 nota-se que a divulgação de informações por segmento iniciou em meados da década de 1960, com a orientação às empresas que publicassem voluntariamente informações complementares em seus demonstrativos. As normas atuais, SFAS 131 e IFRS 8, foram publicadas em 1997 e 2006, respectivamente, apresentando como principal alteração a adoção da abordagem gerencial na estruturação dos relatórios por segmentos. A norma brasileira, o CPC 22, foi elaborada em correlação ao IFRS 8 e publicada em 2009.

No Brasil, no início da década de 1990, a CVM incluiu o tema informações por segmentos nas empresas de forma facultativa, incentivando tal publicação. Esta orientação, no entanto, teve baixíssima adesão por parte das empresas. Os primeiros passos normativos referentes a segmentos no Brasil aconteceram por meio da ANEEL, porém essa legislação 
aplicou-se apenas às companhias de energia elétrica. Somente com a convergência contábil às normas internacionais é que o mercado brasileiro passou a adotar, em 2010, de forma compulsória, a divulgação de relatórios por segmentos.

Sucintamente, estas etapas podem ser entendidas como o início da divulgação de informações por segmentos no mercado brasileiro. A adoção do CPC 22, para as empresas que divulgaram voluntariamente o relatório, torna-se um momento de ajustes ao que a norma exige, agora, de forma compulsória.

\subsection{Pronunciamento Técnico CPC 22}

O Pronunciamento Técnico CPC 22 - Informações por Segmento, em correlação às normas internacionais de contabilidade - IFRS 8, foi editado pelo Comitê de Pronunciamentos Contábeis e passou a vigorar, no Brasil, a partir do exercício de 2010, sob a aprovação dos órgãos reguladores: CVM por meio da Deliberação CVM 582/09, ANEEL a partir do Despacho 4.722/09 e CFC com a Resolução 1.176/09.

O princípio básico da norma é que a empresa deve prestar aos usuários das demonstrações contábeis informações que permitam avaliar a natureza e os efeitos financeiros das atividades de negócios nas quais está envolvida e os ambientes econômicos em que opera, com isso, busca diminuir a assimetria das informações, visando possibilitar aos agentes externos conhecerem os riscos e oportunidades que a empresa oferece.

De acordo com o texto legal, um segmento operacional é qualquer divisão da entidade que desenvolva atividades de negócios nas quais pode obter receitas e incorrer em despesas, que disponibilize informação financeira individualizada e que os resultados sejam regularmente revisados pelo principal gestor de operações para tomada de decisões sobre a alocação de recursos e avaliação de desempenho por segmento. Esclarece a norma que o termo "principal gestor de operações" refere-se à função de alocação de recursos e avaliação de desempenho do segmento, não representando, necessariamente, um gestor com título específico. Portanto, a caracterização do segmento está, essencialmente, conectada à questão da responsabilidade atribuída ao principal tomador de decisões quanto à gestão do segmento, e assim a sua estruturação tende a ser diferente em função do nível hierárquico do principal gestor das operações.

Considerando a abertura proporcionada pela norma ao não definir quem deve ser o principal gestor das operações, o CPC 22 requer que ao determinar o que é um segmento a ser divulgado, as empresas devam observar alguns quesitos.

Assim, dois ou mais segmentos operacionais podem ser divulgados como único segmento, se apresentarem características econômicas semelhantes e se forem semelhantes quanto a:

- natureza dos produtos ou serviços;

- natureza dos processos de produção;

- tipo ou categoria de clientes dos produtos e serviços;

- métodos usados para distribuir os produtos ou prestar os serviços; e

- se aplicável, natureza do ambiente regulatório, por exemplo, bancos, seguros ou serviços de utilidade pública.

A partir da identificação dos segmentos, estes devem ser submetidos a testes para decidir se são divulgáveis ou não. Conforme item 13 do CPC 22 serão divulgáveis os segmentos que atenderem a qualquer um dos seguintes critérios:

- quando a receita auferida pelo segmento é igual ou superior a $10 \%$ da receita de todos os segmentos operacionais;

- quando o lucro ou prejuízo apurado é igual ou superior a $10 \%$ do maior dos seguintes montantes: i) lucro apurado de todos os segmentos que não apresentaram 
prejuízos, e ii) prejuízo apurado de todos os segmentos operacionais que apresentaram prejuízos.

- quando os ativos do segmento representarem $10 \%$ ou mais dos ativos combinados de todos os segmentos.

Complementando a análise, o item 15 da norma requer que o total das receitas externas segmentadas represente, no mínimo, $75 \%$ da receita total da entidade, caso contrário, segmentos operacionais adicionais devem ser incluídos como divulgáveis.

\subsection{Estudos Anteriores}

Até 2010 a divulgação de informações por segmento era feita de forma voluntária, no Brasil, e os estudos mostram que foi praticada por poucas empresas. Vasconselos e Szuster (2003) investigaram publicação de segmentos em 30 companhias abertas brasileiras, e constataram que $17 \%$ delas divulgaram nota explicativa sobre segmentos. O estudo de Schvirck e Gasparetto (2011) pesquisou os demonstrativos de 49 empresas, referentes ao exercício de 2009, constatando que $20 \%$ apresentaram informações por segmento em nota explicativa. Também com dados do exercício de 2009, Cruz et al. (2011) encontraram na amostra de 106 companhias abertas listadas no Novo Mercado da BM\&FBovespa, 13,7\% com publicação de informações por segmento.

Estas pesquisas mostraram a baixa disposição das empresas na divulgação voluntária dos segmentos. Cruz et al. (2011) mostraram que as práticas de evidenciação voluntária das companhias abertas brasileiras do Novo Mercado mostram-se aquém das orientações preconizadas pelo CPC 22 e que o fato de a companhia ser auditada por uma das big four não impactou o nível da publicação, enquanto no estudo de Schvirck e Gasparetto (2011), as empresas listadas no Novo Mercado da BM\&FBovespa apresentaram maior disposição à divulgação voluntária de informações por segmento, entretanto, nenhum dos estudos demonstrou relevância no nível de aderência às prescrições normativas.

Após a promulgação do CPC 22, as pesquisas mostram que a adesão à norma foi significativa. Em todos os estudos realizados com dados a partir de 2010 o percentual de empresas que divulgou o relatório por segmentos foi elevado, em diferentes amostras; sendo que a Ernst Young Terco e FIPECAFI (2011) encontraram 94\% de empresas com divulgação de segmentos. Em Silva e Pinheiro (2012) e Aillón et al. (2013) 79\% das companhias atenderam à norma, e no estudo de Schvirck, Lunkes e Gasparetto (2013), o número de empresas que apresentou o relatório por segmentos foi de $87 \%$.

A discricionariedade dos gestores aliada a itens não exigidos pelo CPC 22 pode fazer com que informações de relativa importância não sejam apresentadas nos relatórios, como as informações por área geográfica. Martin e Poli (2004) explicam que a divulgação de segmentos por área geográfica é relevante para que os acionistas possam avaliar os riscos de investimentos realizados pelas empresas em economias emergentes, e argumentam que a não exigência da divulgação de informações geográficas diminui o poder informativo do relatório por segmentos.

Nichols, Street e Gray (2000) e Hermann e Thomas (2000), a partir de estudos realizados no mercado norte-americano, afirmam que a divulgação de informações geográficas tem sido realizada em menor escala a partir da adoção da abordagem gerencial, por não ser um dado exigido na norma. Para Weissenberger e Franzen (2012) apud Tarca e Pitman (2012), a qualidade do disclosure geográfico a partir da norma IFRS 8 é motivo de preocupação, porque as companhias que divulgam informações por categorias geográficas o fazem de forma muito ampla, como por regiões supranacionais ou continentais, fazendo com que valores relevantes de vendas para o mercado externo não sejam evidenciadas individualmente pelos países a que se referem, o que tende a diminuir a utilidade da informação para o usuário. 
Por outro lado, estudos apontam aumento da evidenciação a partir da implantação do SFAS 131 e IFRS 8. Berger e Hann (2003), em uma amostra de 2.999 empresas, constataram que com o SFAS 131 o número de empresas que apresentaram informações com mais de um segmento passou de $22 \%$ para $40 \%$. Mardini, Crawford e Power (2012) também comentam que com o IFRS 8 aumentou a divulgação de informações segmentadas, tanto em número de empresas que passaram a divulgar como no número de segmentos e de itens divulgados nos relatórios.

Ettredge et al. (2006) afirmam, porém, que o maior número de segmentos divulgados não deve ser suficiente para defender que tenha havido aumento no disclosure, uma vez que muitas empresas, antes do SFAS 131, divulgavam informações em segmento único e, com a adoção da norma e a desagregação dos segmentos, é natural que haja o aumento do número de segmentos, mas isso não necessariamente significa mais informações.

Nesse sentido, Ettredge et al. (2006) estudaram a variabilidade dos lucros em empresas que antes do SFAS 131 já divulgavam informações em múltiplos segmentos, e observaram que: i) houve aumento na informação divulgada acerca da rentabilidade dos segmentos e ii) empresas que com maior necessidade de financiamento externo melhoraram a evidenciação das diferenças entre a rentabilidade dos segmentos.

A divulgação de informações por segmento tende a aumentar a quantidade de informações divulgadas aos agentes externos e, desta forma métricas de rentabilidade diferentes das requeridas pelos padrões contábeis podem ser utilizadas. Nichols, Street e Cereola (2012) relatam que entre 335 blue chips europeias, $83 \%$ usaram, em seus segmentos, medidas de lucro não requeridas pelos padrões normativos, tais como EBIT, EBITDA e lucro operacional. Por outro lado, Crawford et al. (2012), em estudo realizado com empresas do Reino Unido, observaram que a minoria incluiu em seus relatórios por segmento medidas de lucro que não as requeridas pelas normas.

Estudo da KPMG (2010, p.5) mostrou que mais da metade das 81 empresas selecionadas a partir do Fortune Global 500 apresentou o resultado do segmento excluindo algum item, tais como juros, depreciação, amortização ou itens extraordinários. Diversas formas de apuração do resultado foram divulgadas, mas houve consistência na métrica de lucros e perdas utilizada por companhias de um mesmo setor.

A quantidade de segmentos divulgados é uma variável que está relacionada à estrutura organizacional da empresa, e desta forma esse é um dado que apresenta variações em função das empresas utilizadas na amostra. O estudo de Ernst Young Terco e FIPECAFI (2011) encontrou variação entre um e nove segmentos em amostra de 56 empresas, sendo que $23 \%$ informaram atuar em apenas um segmento. Na reedição do estudo, em 2012, com amostra de 60 empresas, o grupo com apenas um segmento foi de 25\%, já as companhias com múltiplos segmentos variaram entre dois e sete segmentos divulgados (ERNST YOUNG TERCO e FIPECAFI, 2012). Os dados são similares aos achados de Schvirck, Lunkes e Gasparetto (2013), que mostram variação entre um e nove segmentos divulgados, e $27 \%$ de empresas que atuam em segmento único.

O critério para definição dos segmentos divulgáveis também é um item que pode apresentar variação de uma empresa para outra, no entanto, os estudos mostram similaridade nos resultados. Em 2011 a Ernst Young Terco e FIPECAFI encontraram 61\% de empresas que utilizaram a linha de negócios como critério de definição de segmentos, $32 \%$ utilizaram a área geográfica e $7 \%$ utilizaram os dois critérios combinados. De acordo com Aillón et al. (2013), 66\% definiram os segmentos por linha de negócios, 26\% por área geográfica e 8\% utilizaram a combinação das duas formas de divulgação.

A predominância do critério de linhas de negócios ou produtos e serviços foi demonstrada também no relatório da Ernst Young Terco e FIPECAFI (2012), onde 76\% das empresas utilizaram esse critério, $7 \%$ adotaram a área geográfica, 15\% divulgaram com 
ambos os critérios e $2 \%$ fizeram uso de outras formas de definição. Para Silva e Pinheiro (2012), o critério de produtos e serviços foi adotado por $66 \%$ das empresas, $11 \%$ divulgaram por área geográfica, $17 \%$ combinaram os dois critérios e $6 \%$ utilizaram outros critérios. A pesquisa de Schvirck, Lunkes e Gasparetto (2013) encontrou 86\% das empresas com segmentos por produtos e serviços, $11 \%$ por área geográfica e $3 \%$ com a combinação dos critérios.

Em relação à aderência quanto ao tipo de informação requisitada pela norma, os estudos apresentam semelhanças ao demonstrar que alguns itens são atendidos por quase todas as empresas, tais como valores de receitas, resultados e ativos, por outro lado, informações sobre a dependência de clientes, conciliações e informações entre segmentos são os dados menos divulgados (ERNST YOUNG TERCO e FIPECAFI, 2011; SILVA e PINHEIRO, 2012; ERNST YOUNG TERCO e FIPECAFI, 2012; AILLÓN et al., 2013).

As diferenças nas estruturas organizacionais são definidas por fatores diversos, tamanho, setor e região de atuação, modelo de gestão, entre outros, e isso influencia a forma de divulgação das informações. Aillón et al. (2013) mostram que há tendência de que as empresas com resultados positivos estejam dispostas a divulgar mais informações por segmentos do que as que apresentam resultados negativos; enquanto, Silva e Pinheiro (2012) e Schvirck, Lunkes e Gasparetto (2013) encontraram relacionamento positivo e significante entre o tamanho das empresas e a divulgação de segmentos.

Os estudos realizados no mercado brasileiro após a vigência do CPC 22 apresentam resultados semelhantes no que tange às características da informação divulgada, ou seja, há maior incidência de empresas que definem seus segmentos a partir da linha de negócios ou produtos, seguindo a prática adotada por companhias internacionais que já publicam informações por segmento há mais tempo. Quanto ao tipo de informações divulgadas, alguns itens como a representatividade dos clientes é pouco evidenciada e há companhias que agregam seus resultados em apenas um segmento, ou seja, não apresentam informações além dos dados consolidados.

\section{PROCEDIMENTOS METODOLÓGICOS}

Este estudo, de acordo com o escopo proposto em seu objetivo, tem caráter descritivo por apresentar as características da divulgação de segmentos de forma voluntária e as alterações ocorridas em função da normatização e das exigências da publicação destas informações.

A pesquisa foi desenvolvida nos relatórios das companhias que compunham o índice IBrX-50 em dezembro de 2012, em função da alta liquidez e representatividade destas organizações dentre as companhias listadas na BM\&FBOVESPA. O IBrX-50 é um índice que mede o retorno total de uma carteira teórica composta por 50 ações selecionadas entre as mais negociadas na BM\&FBOVESPA em termos de liquidez, ponderadas na carteira pelo valor de mercado das ações disponíveis à negociação (BM\&FBOVESPA, 2012).

Considerando que algumas empresas figuram no índice com diferentes ações, ajustouse a amostra em função das empresas participantes e não das ações que as representam na composição do IBrX-50. Desta forma, a amostra utilizada no estudo foi composta por 47 companhias abertas com atuação no mercado brasileiro.

Foram pesquisadas as notas explicativas das demonstrações publicadas, identificando se ocorreu divulgação de informações por segmento nos anos de 2008 e 2009, quando essa evidenciação era voluntária, e nos anos de 2010 e 2011, quando a divulgação passou a ser compulsória em função da vigência do CPC 22.

Após, para as empresas que divulgaram informações por segmento antes da vigência do CPC 22 (2008 e 2009), foi verificada a estrutura dos relatórios. Foram lidas as notas 
explicativas para identificar as características da divulgação voluntária e compulsória. Os itens pesquisados no levantamento foram:

- se a empresa publicou voluntariamente (anos de 2008 e 2009) ou compulsoriamente (2010 e 2011) informações por segmentos;

- quantos segmentos foram divulgados;

- qual a forma utilizada pela empresa para definir os segmentos operacionais;

- de que forma foi apresentado o resultado da empresa - com qual métrica foi apurado; e

- se a empresa informa quem é o principal gestor de operações, e qual sua função hierárquica.

A análise de dados foi realizada de forma qualitativa e utilizou-se estatística descritiva para a caracterização da divulgação realizada pelas empresas.

\section{RESULTADOS DA PESQUISA}

O estudo desenvolvido no grupo de 47 companhias mostrou que a divulgação voluntária, nos anos de 2008 e 2009, aconteceu em $17 \%$ e $21 \%$ das empresas, respectivamente. Estes resultados se assemelham aos estudos de Vasconselos e Szuster (2003), Cruz et al. (2011) e Schvirck e Gasparetto (2011) quanto ao baixo índice de empresas que divulgaram informações por segmento de forma voluntária. Destaca-se que duas empresas que divulgaram informações em 2008 não o fizeram em 2009, e quatro empresas divulgaram somente em 2009, como mostra a

Quadro 2: Empresas que apresentaram relatório por segmentos antes e depois do CPC 22 .

Após a vigência do CPC 22 o número de empresas que divulgou informações por segmento foi de $96 \%$ da amostra, esse resultado mostra que o enforcement normativo surtiu efeito ao estabelecer a divulgação compulsória das informações por segmentos. No entanto, somente 12 empresas (13\% da amostra) publicaram o relatório em todo o período estudado, ou seja, de forma voluntária e também compulsória. Desta forma, de acordo com o objetivo do estudo, foram analisados os relatórios por segmentos destas 12 companhias, conforme mostra o Quadro 2.

Quadro 2: Empresas que apresentaram relatório por segmentos antes e depois do CPC 22

\begin{tabular}{|l|c|c|c|c|}
\hline \multirow{2}{*}{ Empresa } & \multicolumn{4}{c|}{ Exercícios em que divulgou relatório por segmentos } \\
\cline { 2 - 5 } & $\mathbf{2 0 0 8}$ & $\mathbf{2 0 0 9}$ & $\mathbf{2 0 1 0}$ & $\mathbf{2 0 1 1}$ \\
\hline Banco Bradesco SA & $\mathrm{X}$ & $\mathrm{X}$ & $\mathrm{X}$ & $\mathrm{X}$ \\
\hline BR Malls Participaçóes SA & & $\mathrm{X}$ & $\mathrm{X}$ & $\mathrm{X}$ \\
\hline Cia Bebidas das Américas - AMBEV & & $\mathrm{X}$ & $\mathrm{X}$ & $\mathrm{X}$ \\
\hline Cia Siderúrgica Nacional & $\mathrm{X}$ & $\mathrm{X}$ & $\mathrm{X}$ \\
\hline COSAN SA Indústria e Comércio & $\mathrm{X}$ & $\mathrm{X}$ & $\mathrm{X}$ & $\mathrm{X}$ \\
\hline Gafisa SA & $\mathrm{X}$ & $\mathrm{X}$ & $\mathrm{X}$ & $\mathrm{X}$ \\
\hline Gerdau SA & & $\mathrm{X}$ & $\mathrm{X}$ & $\mathrm{X}$ \\
\hline Natura Cosméticos SA & & $\mathrm{X}$ & $\mathrm{X}$ & $\mathrm{X}$ \\
\hline Oi SA & $\mathrm{X}$ & $\mathrm{X}$ & $\mathrm{X}$ \\
\hline Petróleo Brasileiro SA - Petrobras & $\mathrm{X}$ & $\mathrm{X}$ & $\mathrm{X}$ & $\mathrm{X}$ \\
\hline Souza Cruz SA & $\mathrm{X}$ & $\mathrm{X}$ & $\mathrm{X}$ & $\mathrm{X}$ \\
\hline Vale SA & $\mathrm{X}$ & $\mathrm{X}$ & $\mathrm{X}$ & $\mathrm{X}$ \\
\hline
\end{tabular}

Fonte: Dados da pesquisa

Nessas empresas, a normatização pouco afetou o número de segmentos publicados, conforme demonstra a Tabela 1 Erro! Fonte de referência não encontrada.. Nota-se que em 
2010 o número médio de segmentos divulgados diminuiu em relação aos anos de divulgação voluntária. Três empresas diminuíram o número de segmentos antes e depois da adoção do CPC 22 e uma aumentou. Nas empresas analisadas neste período não houve variação no número mínimo de segmentos divulgados, permanecendo em três segmentos.

$\mathrm{O}$ número médio de segmentos divulgados pelas companhias brasileiras, com a vigência da norma mostrou-se semelhante aos estudos de Hermann e Thomas (2000) que encontraram em média 3,8 segmentos e inferiores aos achados de Nichols, Street e Cereola (2012) que mostram que em média as empresas europeias divulgam 4,4 segmentos operacionais.

Tabela 1: Número de segmentos divulgados pelas empresas

\begin{tabular}{lcccc}
\hline & $\mathbf{2 0 0 8}$ & $\mathbf{2 0 0 9}$ & $\mathbf{2 0 1 0}$ & $\mathbf{2 0 1 1}$ \\
\hline Número médio de segmentos & 4,25 & 4,1 & 3,8 & 4,1 \\
Menor número de segmentos & 3 & 3 & 3 & 3 \\
Número máximo de segmentos & 6 & 6 & 6 & 7 \\
\hline
\end{tabular}

Dentre as empresas que divulgaram informações antes e depois do CPC 22, observaram-se variações no número de segmentos em algumas delas. O Bradesco apresentou em 2008 e 2009 dois segmentos principais, i) atividades financeiras e ii) grupo segurador, subdivididos em 'país' e 'exterior' e mais uma coluna com informações de 'outras atividades', perfazendo assim cinco segmentos de operações. A partir de 2010 o relatório mostrou apenas três segmentos: i) setor bancário, ii) seguros, previdência e capitalização e ii) outras operações. Assim, a empresa deixou de divulgar informações geográficas - atividades no país e exterior.

A Gafisa declara atuar em dois segmentos de negócios definidos em função da renda dos clientes, no entanto, por atuar no ramo imobiliário a empresa mantém projetos que não estão enquadrados nesta classificação, e que são extintos quando concluídos. Assim, em 2008 a empresa apresentou cinco segmentos, sendo dois especificados e mais três projetos em andamento. Em 2009, 2010 e 2011, entretanto, somente um destes projetos permaneceu em execução, assim sendo, apesar de a empresa declarar que opera em dois segmentos, em seu relatório constaram, nesse período, informações referentes a três negócios.

A companhia Oi agrupou dois segmentos de serviços publicados antes do CPC $22 \mathrm{em}$ apenas um, dessa forma diminuiu de quatro para três segmentos após a adoção da norma. Por outro lado a Companhia Siderúrgica Nacional (CSN) desmembrou informações de suas linhas de negócios e aumentou de três para cinco segmentos no período posterior à adoção do CPC 22.

Em 2011 a Cosan passou de três para cinco segmentos conforme explicado em nota da empresa: "tendo em vista a formação das JVs Raízen Energia, Raízen Combustíveis e a aquisição dos negócios de varejo de açúcar da Raízen, a Cosan modificou a apresentação de seus segmentos, passando a apresentar cinco segmentos". A Petrobras aumentou o número de segmentos de 2010 para 2011 devido à criação de segmento específico para o negócio de biocombustíveis.

O aumento do número de empresas que divulgam informações por segmento e a variação do número de segmentos divulgados também foi encontrada nos estudos de Berger e Hann (2003) e Mardini, Crawford e Power (2012). O número de segmentos divulgados, no estudo de Nichols, Street e Cereola (2012), permaneceu inalterado em 62\% da amostra, mas houve aumento em $27 \%$ das empresas e também $11 \%$ diminuíram o número de segmentos divulgados. Estes estudos foram realizados no âmbito de atuação do IFRS 8 e SFAS 131.

$\mathrm{Na}$ amostra desta pesquisa, também se observou que a forma de definição dos segmentos divulgáveis pouco se alterou em função da regulamentação, conforme mostra a Tabela 2 Erro! Fonte de referência não encontrada. Nota-se a predominância do critério de 
linha de produtos nos quatro anos analisados, assim como nos estudos internacionais. Esse resultado corrobora a afirmação e Frezatti et al (2009) em relação à maior utilização da segmentação por linha de produtos ou serviços. Com exceção do Bradesco, que divulgava segmentos de forma combinada, e passou a utilizar a linha de produtos, conforme já exposto anteriormente, todas as outras empresas mantiveram o critério que utilizavam na forma voluntária de divulgação.

Tabela 2: Número de empresas que adotou cada tipo de segmento

\begin{tabular}{lcccc}
\hline & $\mathbf{2 0 0 8}$ & $\mathbf{2 0 0 9}$ & $\mathbf{2 0 1 0}$ & $\mathbf{2 0 1 1}$ \\
\hline Linha de produtos & 6 & 4 & 7 & 7 \\
Geográfico & - & 1 & 1 & 1 \\
Linha de negócios e geográfico & - & 1 & 1 & 1 \\
Critérios combinados & 2 & 4 & 3 & 3 \\
\hline
\end{tabular}

Os resultados desta pesquisa podem ser comparados a com outros que apresentaram situações distintas em relação à forma de definição dos segmentos. Nos estudos de Martin e Poli (2004), Nichols, Street e Gray (2000) Hermann e Thomas (2000) e Weissenberger e Franzen (2012) citados por Tarca e Pitman (2012), a divulgação de informações geográficas diminuiu com o advento do IFRS 8 e SFAS 131, prevalecendo segmentos por linha de negócios. Nota-se na Tabela 2 que a quantidade de empresa que divulgou segmentos geográficos permaneceu inalterado, no entanto, esse número representa menos de $10 \%$ da amostra.

Por outro lado, Nichols, Street e Cereola (2012) mostraram que a abordagem gerencial adotada pelo IFRS 8 permitiu a combinação de diferentes critérios, o que não era permitido pelo IAS 14. O CPC 22, por ser baseado no IFRS 8 , permite às companhias a combinação de critérios, nota-se que tal situação ocorreu em três companhias.

Nos critérios combinados, as companhias divulgam parte das informações por linha de negócios e parte por atuação geográfica. A Petrobras, em 2008, 2009 e 2010, divulgou cinco segmentos de negócios e um de atividades internacionais, e em 2011 passou a divulgar sete segmentos com a inclusão de um segmento de negócios. A Gerdau prioriza a informação geográfica e combina três segmentos geográficos, com um de linha de produto.

No caso da BR Malls Participações a combinação de critérios leva em consideração a classe social dos clientes como uma forma de segmentação e as informações são divulgadas também por atuação geográfica.

A abordagem gerencial adotada no CPC 22 possibilitou às empresas utilizarem métricas de lucros não normatizadas. Nota-se na Tabela 3que, na amostra pesquisada, nos anos de 2008 e 2009 as métricas divulgadas restringiram-se a métodos normativos, especialmente o lucro líquido do exercício. Já o advento do CPC 22 trouxe para os relatórios por segmentos métricas com maior foco na gestão das empresas, como o EBITDA, utilizado por $17 \%$ das empresas, e o lucro operacional, empregado por $25 \%$, consequentemente o lucro líquido do exercício foi utilizado por menor número de empresas após o CPC 22, mas ainda é a principal métrica de resultado divulgada.

Tabela 3: Métrica de resultado divulgada nos relatórios por segmento

\begin{tabular}{lcccc}
\hline & $\mathbf{2 0 0 8}$ & $\mathbf{2 0 0 9}$ & $\mathbf{2 0 1 0}$ & $\mathbf{2 0 1 1}$ \\
\hline Lucro líquido do exercício & $75 \%$ & $80 \%$ & $58 \%$ & $58 \%$ \\
Resultado bruto & $13 \%$ & $20 \%$ & - & - \\
EBITDA & - & - & $17 \%$ & $17 \%$ \\
Lucro operacional & - & - & $25 \%$ & $25 \%$ \\
Lucro operacional antes do resultado financeiro & $13 \%$ & - & - & - \\
\hline
\end{tabular}


Esses resultados assemelham-se ao contexto internacional apresentado no relatório da KPMG (2010, p.14), que indica a utilização do lucro operacional por $21 \%$ das 81 companhias de sua amostra, 9\% informam o EBITDA e outros 9\% apontam o EBIT como medida de resultado utilizada pelo principal gestor. O estudo de Nichols, Street e Cereola (2012) mostrou também aumento na utilização de medidas de lucro ajustadas, diferente do exigido em legislação, já para Crawford et al. (2012) a flexibilização da norma pouco alterou a forma de divulgação de lucros pelas empresas

O CPC 22 determina que a definição dos segmentos seja realizada em função das informações para a tomada de decisões do principal gestor de operações, no entanto não há uma designação de quem deve exercer tal função. Desta forma, investigou-se, se as companhias identificaram no relatório quem é o principal gestor de operações. Os resultados são apresentados na Tabela 4, com destaque para a administração da empresa, citado por 50\% das companhias.

Tabela 4: Principal gestor de operações informado pelas empresas

\begin{tabular}{|c|c|c|c|}
\hline 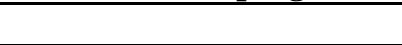 & $2008 \quad 2009$ & 2010 & 2011 \\
\hline Conselho de administração & & $8 \%$ & $8 \%$ \\
\hline Administração da empresa & & $50 \%$ & $50 \%$ \\
\hline Diretoria administrativa & & $25 \%$ & $25 \%$ \\
\hline Comitê executivo & & $17 \%$ & $17 \%$ \\
\hline
\end{tabular}

O estudo de Nichols, Street e Cereola (2012) identificou em 36\% das empresas de sua amostra, que o principal gestor de operações foi designado como o conselho diretor, a alta administração ou o presidente. No relatório da KPMG (2010, p.7), 31\% das companhias identificaram a diretoria executiva como o principal gestor de operações, o CEO foi indicado em $6 \%$ das empresas e $61 \%$ não informaram.

Algumas empresas alteraram em seu relatório o tipo de informações divulgadas ao longo do período, possivelmente pela orientação gerencial do relatório. O Bradesco publicou, até 2009, dados detalhados do ativo, do passivo e dos resultados da companhia, e a partir de 2010 priorizou informações sobre os resultados, e os valores de ativos e passivos foram publicados apenas pelo total.

A Cosan divulgou poucas informações em 2008 e 2009, resumindo-se a receita, lucro bruto e principais clientes de cada segmento. A partir de 2010 foram incluídas informações sobre ativos e passivos e mais detalhes da composição dos resultados da companhia.

Antes da adoção do CPC 22 a Oi divulgou o relatório com valores sintetizados de custos e despesas. Nos anos de 2010 e 2011 incluiu rubricas detalhando os custos e despesas, ampliando assim o nível de informação dos segmentos.

A Companhia Siderúrgica Nacional (CSN) apresentou menor quantidade de informações após adoção do CPC 22. Anteriormente a empresa divulgava o balanço patrimonial e a demonstração de resultados completa, já os relatórios atuais apresentam as informações de forma selecionada, incluindo métricas de resultado não publicadas nas demonstrações consolidadas, como o EBITDA, no entanto, não divulga dados referentes ao ativo e passivo.

Depreende-se do exposto que a adoção do CPC 22 nas práticas de divulgação das empresas proporcionou alterações na forma de elaboração e publicação das informações sobre segmentos. A utilização da abordagem gerencial permite que as companhias publiquem os relatórios de acordo com a particularidade da sua estrutura administrativa e, assim, o tipo de segmento, a quantidade e o nível de informação são definidos de acordo com o relatório elaborado para o principal gestor de operações da companhia. 


\section{CONSIDERAÇÕES FINAIS}

As informações por segmento objetivam fornecer aos agentes interessados nas companhias informações com detalhes que as demonstrações consolidadas não proporcionam. A instituição do CPC 22 no mercado brasileiro representou, efetivamente, aumento de informações aos usuários das demonstrações contábeis, visto que das empresas estudadas somente $13 \%$ divulgavam segmentos antes da adoção da norma, e posteriormente $96 \%$ das companhias apresentou o relatório.

As empresas brasileiras que divulgaram segmentos antes do CPC 22 o fizeram de forma voluntária por orientações da CVM, tendo por base as premissas do IAS 14. Deste modo, quando adotaram a norma atual, algumas realizaram ajustes nos seus relatórios.

$\mathrm{O}$ uso da abordagem gerencial implica em maior discricionariedade aos gestores na definição de como divulgar as informações, visto que empresas que publicavam as demonstrações completas segmentadas passaram a divulgar informações selecionadas e com itens que não são requeridos em norma, tal como métricas gerenciais de resultado.

A alteração do número de segmentos divulgados não se caracteriza diretamente como um ajuste em função da norma, considerando que esta é uma característica da empresa. No entanto, a flexibilização possibilitada pelo CPC 22 com a divulgação de acordo com a estrutura gerencial, permite aos gestores definirem os segmentos da maneira que, ao seu juízo, melhor representem as informações da empresa. Nas empresas estudadas houve pouca variação no número de segmentos divulgados voluntária ou compulsoriamente, já que somente quatro empresas alteraram o número de segmentos, sendo que três diminuíram e uma aumentou o número de segmentos divulgados.

O critério de definição dos segmentos divulgados não se alterou. Mesmo com a possibilidade de divulgar segmentos sob qualquer estrutura existente na empresa, manteve-se a predominância pelos segmentos por linha de negócios, demonstrando assim que o modelo de gestão utilizado pelas empresas foca principalmente na tomada de decisões por linha de produtos.

A informação de quem é o principal gestor de operações foi uma das contribuições do CPC 22, pois ao conhecer a posição hierárquica do tomador de decisões, em nível de conselho de administração ou então de presidência da companhia, o usuário tem condições de identificar a estrutura administrativa da empresa e como as decisões estratégicas são encaminhadas na gestão da companhia.

Conclui-se, portanto, que a adoção do CPC 22 nas empresas pesquisadas que divulgaram informações por segmento de forma voluntária até 2009, impactou na estrutura das demonstrações. Foram encontradas poucas alterações nas informações das empresas estudadas, no entanto, os ajustes apontados tendem a melhorar o poder informativo dos relatórios ao utilizar dados selecionados e, principalmente, ao expor aos usuários da informação contábil os relatórios com a estrutura que é repassada ao gestor principal para a tomada de decisões.

\section{REFERÊNCIAS}

AILLÓN, Humberto Silva; SILVA, Julio Orestes; PINZAN, Anderson Ferreira; WUERGES, Artur Filipe Ewald. Análise das informações por segmento: divulgação de informações gerenciais pelas empresas brasileiras. Revista Contemporânea de Contabilidade - UFSC. Florianópolis, v. 10, n. 19, p. 33-48, jan/abr. 2013. http://dx.doi.org/10.5007/27158069.2013v10n19p33. 
ANEEL - Agência Nacional de Energia Elétrica. Resolução ANEEL No 001/1997, de 24 de dezembro de 1997.

ANEEL - Agência Nacional de Energia Elétrica. Resolução ANEEL No 444/2001, de 26 de outubro de 2001.

ANEEL - Agência Nacional de Energia Elétrica. Despacho ANEEL No 4722/2009, de 18 de dezembro de 2009.

BERGER, Philip G.; HANN, Rebecca. The impact of SFAS $\mathrm{N}^{\circ} 131$ on information and monitoring. Journal of Accounting Research. v. 41, n. 2, maio 2003. http://dx.doi.org/10.1111/1475-679X.00100

BMFBOVESPA.

Disponível

em:

$<$ http://www.bmfbovespa.com.br/indices/ResumoIndice.aspx?Indice=IBrX50\&Idioma=ptbr>.

CFC - Conselho Federal de Contabilidade. Resolução CFC 1.176/09 de 24 de julho de 2009. Aprova a NBC TG 22 - Informações por segmento.

CPC - Comitê de Pronunciamentos Contábeis. Pronunciamento técnico CPC 22: Informações por segmento. 2009. Disponível em: 〈http://www.cpc.org.br>. Acessado em novembro de 2011.

CRAWFORD, Louise; EXTANCE, Heather., HELLIAR, Christine.;POWER, David. Operating segments: the uselfulness of IFRS. ICAS Insight, Edinburgh, 2012.

CRUZ, Ana Paula Capuano da; MACHADO, Esmael Almeida; PEREIRA, Anderson Feitosa; CARVALHO, L. Nelson. Empresas brasileiras do novo mercado e suas práticas de evidenciação voluntária de informações por segmento. In: CONGRESSO ANPCONT, 5, 2011, Vitória/ES. Anais... Vitória, ANPCONT, 2011. CD-ROM.

CVM - Comissão de Valores Mobiliários. Parecer de orientação CVM No 24, de 15 de janeiro de 1992.

CVM - Comissão de Valores Mobiliários. Ofício-Circular/CVM/SNC/SEP No 01/2004, de 19 de janeiro de 2004.

CVM - Comissão de Valores Mobiliários. Deliberação CVM N 582, de 31 de julho de 2009 - Aprova o Pronunciamento Técnico CPC 22 do Comitê de Pronunciamentos Contábeis, que trata de informações por segmento.

ERNST YOUNG TERCO; FIPECAFI. IFRS: $1^{\circ}$ Ano. Análises sobre a adoção inicial do IFRS no Brasil. São Paulo. Disponível em: <http://www.ey.com/Publication/vwLUAssets/FIPECAFI_1_ano_de_IFRS/\$FILE/Fipecafi_B aixa.pdf $>$, acessado em 08.11.2011

ERNST YOUNG TERCO; FIPECAFI. IFRS: Análises sobre o IFRS no Brasil. São Paulo. Disponível em: <http://www.ey.com/Publication/vwLUAssets/Estudo_FIPECAFI__2012/\$FILE/Fipecafi.pdf>, acessado em 09.11.2012 
ETTREDGE, Michael L.; KWON, Soo Young; SMITH. David B.; STONE, Mary S. The effect of SFAS $\mathrm{N}^{\circ} 131$ on the cross-segment variability of profits reported by multiple segment firms. Review Accounting Studies, v. 17, p. 91-117, 2006. http://dx.doi.org/10.1007/s11142-006-6397-9

FASB - Financial Accounting Standards Board. SFAS 131 - Disclosure about Segments of an Enterprise and Related Information. Junho/1997. Disponível em: <http://www.fasb.org.>. Acessado em novembro de 2011.

FREZATTI, Fábio; ROCHA, Wellington; NASCIMENTO, Artur R.; JUNQUEIRA, Emanuel. Controle gerencial: uma abordagem da contabilidade gerencial no contexto econômico, comportamental e sociológico. São Paulo: Atlas, 2009.

HERRMANN, Don; THOMAS, Wayne B. An analysis of segment disclosures under SFAS N. 131 and SFAS N. 14. Accounting Horizons. v. 14, n. 3, p. 287-302, 2000. http://dx.doi.org/10.2308/acch.2000.14.3.287

IASB - International Accounting Standards Board, IFRS 8: Operating Segments. Disponível em: <http://www.iasb.org.>. Acessado em novembro de 2011.

MARDINI, Ghassan H.; CRAWFORD, Louise; POWER, David M. The impact of IFRS 8 on disclosures practices of Jordanian listed companies. Journal of Accounting in Emerging Economies. v.2, n.1. 2012. http://dx.doi.org/10.1108/20421161211196139

MARTIN, Anna D.; POLI, Patrícia M. The usefulness of geographic segment disclosure for U.S. based MNCs operating in emerging markets. Advances in International Accounting. v. 17, p. 199-225, 2004. http://dx.doi.org/10.1016/s0897-3660(04)17010-4

MOURAD, Nabil Ahmad. IFRS 8 - Segmentos operacionais: contabilidade internacional: International Financial Reporting Standards - IFRS. São Paulo: Atlas, 2009.

NICHOLS, Nancy B.; STREET, Donna L.; GRAY, S. J. Geographic segment disclosures in the United States: reporting practices enter a new era. Journal of International Accounting, Auditing \& Taxation. v. 9, n. 1, pp. 59-82, 2000. http://dx.doi.org/10.1016/S10619518(00)00025-2

NICHOLS, Nancy B.; STREET, Donna L.; CEREOLA, Sandra. An analysis of the impact of applying IFRS 8 on the segment disclosures of European blue chips companies. Journal of International Accounting Auditing and Taxation. v. 22, n. 2, 2012. http://dx.doi.org/10.1016/j.intaccaudtax.2012.07.001

SCHVIRCK, Eliandro; GASPARETTO, Valdirene. Divulgação voluntária de informações por segmento e governança corporativa antes da vigência do CPC 22. In: EnANPAD, 35, 2011, Rio de Janeiro. Anais... Rio de Janeiro: ANPAD, 2011.

SCHVIRCK, Eliandro; LUNKES, Rogério João; GASPARETTO, Valdirene. Divulgação de informações por segmento: panorama da aplicação do CPC 22. Revista de Pesquisa e Educação em Contabilidade - REPeC. v. 7, n. 2, p. 134-149, abr/jun 2013. 
SILVA, Flávia de Araújo; PINHEIRO, Laura Edith Taboada. Estágio atual de evidenciação e fatores que influenciam o disclosure de informações por segmentos por empresas brasileiras. Revista de Contabilidade e Controladoria. v. 4, n. 3, p. 78-94, set/dez 2012.

TARCA, Ann; PITMAN, April. Post-implementation review of IFRS 8. IAS Agenda ref 12 B. Disponível em: <http://www.eiasm.org/userfiles/IFRS8-0612b12B-AMENDED.pdf>, acessado em 02.07.2012.

VASCONSELOS, Madson de Gusmão; SZUSTER, Natan. Informações contábeis por segmento de negócios. Revista de Contabilidade do Mestrado em Ciências Contábeis da UERJ. v. 8, n. 2, p. 71-88, Rio de Janeiro, 2003. 